\title{
Acute intraocular toxicity caused by perfluorocarbon liquids: safety control systems of medical devices
}

\author{
Girish K. Srivastava ${ }^{1,2} \cdot$ Vivekanandan Kalaiselvan $^{3} \cdot$ Cristina Andrés-Iglesias $^{1} \cdot$ Shatrunajay Shukla $^{3} \cdot$ Rohit Saxena $^{4}$. \\ Jose Carlos Pastor ${ }^{1,2,5}$
}

Received: 8 November 2021 / Revised: 20 January 2022 / Accepted: 24 January 2022 / Published online: 5 February 2022

(c) The Author(s), under exclusive licence to Springer-Verlag GmbH Germany, part of Springer Nature 2022

\begin{abstract}
Background Acute retinal toxicity has been demonstrated to be associated with the intraoperative use of perfluorocarbon liquids (PFCLs), especially perfluorooctane (PFO). Recently, several cases of PFO-associated blindness have been reported in Spain, Holland, France, Italy, the Middle East, and South America.

Methods As a result, a new ISO guideline (ISO 16672:2020) was drafted, discussed, approved, and released in 2019. This recent ISO16672:2020 guideline recommends performing direct cytotoxicity tests as an option along with chemical analysis to measure PFCL quality (purity and safety).

Results In this review paper, it has been emphasized why an appropriate biological test, specifically direct exposure of PFCL to live cells, for measuring cytotoxicity must be performed with each PFCL batch along with chemical analysis.

Conclusions The paper intends to compile all available information to discuss possible approaches for avoiding adverse clinical cases in future.
\end{abstract}

Keywords Retinal toxicity $\cdot$ PFO toxicity $\cdot$ PFO clinical cases $\cdot$ Direct cytotoxicity test $\cdot$ ISO guidelines

\section{Key messages}

- Visual loss caused by Perfluorocarbon liquids.

- Need of robust ISO/FDIS 16672.2 guideline and regulatory agencies communications at international level.

- Direct cytotoxicity tests and chemical analysis requirements to measure quality of each lot of PFCL to avoid visual loss.

Girish K. Srivastava

girish@ioba.med.uva.es

Vivekanandan Kalaiselvan

kalaiselvan.ipc@gov.in

Cristina Andrés-Iglesias

candresi@ioba.med.uva.es

Shatrunajay Shukla

shatrunjay.ipc@gov.in

Rohit Saxena

rohitsaxena80@yahoo.com

Jose Carlos Pastor

pastor@ioba.med.uva.es
1 Instituto Universitario de Oftalmobiología Aplicada (IOBA), Universidad de Valladolid, Valladolid, Spain

2 Centro en Red de Medicina Regenerativa y Terapia Celular de Castilla Y León, Valladolid, Spain

3 Indian Pharmacopoeia Commission, Ministry of Health \& Family Welfare, Government of India, Sector-23, Raj Nagar, Ghaziabad 201002, Uttar Pradesh, India

4 Rajendra Prasad Centre for Ophthalmic Sciences, All India Institute of Medical Sciences, Delhi, India

5 Oftared, National Institute of Health Carlos III, Madrid, Spain 


\section{Introduction}

Worldwide, in recent years, several ophthalmologists have reported cases of blindness after intraocular surgery due to acute toxicity of the perfluorocarbon liquids (PFCLs), mainly perfluorooctane (PFO) [1-3]. The corresponding governmental authorities have released informative notes for hospitals, medical staff, patients, and the general public having withdrawn the lots from the market [1-3]. There has also been a sudden increase in the numbers of papers published in the last 4 years (2016-2020) reporting cases in Spain, Holland, France, Italy, Switzerland, the Middle East, and Chile (Table 1) [1-6]. In Spain, to the best of our knowledge, most of these cases are under legal proceedings to receive compensation. It is reported that the affected manufacturers have stopped the PFCL production (Bio Octane Plus®, Biotech Ophthalmology PVT Ltd, Gujarat, India; AlaOcta ${ }^{\circledR}$, AlaMedics, Dornstadt, Germany; Meroctane ${ }^{\circledR}$, Meran Tip Ltd., Istanbul, Turkey). The German company AlaMedics even has declared bankruptcy. The situation has resulted in tense discussions in different international meetings. The ophthalmologists are uncertain for PFCL safe for use as well as manufacturers for the future of the PFCL market. According to European and US regulations, the quality assurance (QA) applying appropriate testing methods is one of the essential requirements for commercialization of any medical device including for those used intraocular such as PFCL.

Interestingly, all of these reported toxic PFCL batches were "Conformité Européenne (CE)" marked that is a QA certification for selling them in the European market [7]. The CE-mark represents a guarantee of quality for any medical device and, in the case of PFCL, which is used for intraocular surgery, certifies that it is safe for use. The users, essentially the hospitals and medical staff, ensure the CE-mark before using a PFCL batch in patients. In the European Union, a commercialized product has to accomplish the standards and recommendations of the International Organization for Standardization (ISO) and the European Union Medical Device Regulation (EU-MDR 2017/245) during manufacturing, and biological and chemical analytical tests. Similar to the

Table 1 Perfluorocarbon liquid toxicity cases

\begin{tabular}{llll}
\hline Country & $\begin{array}{l}\text { Number of } \\
\text { clinical cases* }\end{array}$ & PFCL product & References \\
\hline Chile & 14 cases & Meroctane ${ }^{\circledR}$ & Coco et al. [28] \\
Spain & 4 cases & Meroctane ${ }^{\circledR}$ & Coco et al. [28] \\
Spain & 4 cases & BioOctane Plus ${ }^{\circledR}$ & Coco et al. [3] \\
Switzerland & 48 cases & AlaOcta ${ }^{\circledR}$ & Tobalem et al. [5] \\
Spain & 120 cases & AlaOcta ${ }^{\circledR}$ & Pastor et al. [1] \\
\hline
\end{tabular}

*Number of clinical cases, to the best of our knowledge, or reported in recent publications
European Union, in the USA, the United States Pharmacopeia (USP) releases standards-based documentary evidence and physical references for medicines, food ingredients, and dietary supplement products, and ingredients. The US regulatory agencies and manufacturers use these standards to ensure the identity, strength, quality, purity, and consistency of the products $[8,9]$. The importance of customer complaints for providing valuable information on the use of medical devices is clearly reflected in the United States (US) and the European quality system requirements for handling complaints. However, there are significant differences in US and European complaint handling requirements [10]. Nevertheless, recent reported cases of the PFCL toxicity have raised doubts and questions in the medical and patient community. In India, the Indian Pharmacopoeia Commission and Indian National Regulatory Authority, i.e., CDSCO (Central Drugs Standard Control Organization), release regulatory documents. They perform vigilance through the regional medical device adverse events monitoring centers (there are 150 such centres pan India). The regulation of medical devices across the world is very varied, ranging from comprehensive to none [11]. However, the increasing numbers of reports in recent years published for adverse events due to some PFCL batches and other medical devices (intraocular lenses and vital dies used for visualization of epiretinal membranes and inner limiting membrane (ILM) peeling) $[4,12]$ in different countries confirm that one or several of the recommendations and standards have failed. Consequently, it becomes essential worldwide to focus on quality standards and recommendations to ensure that only high-quality, pure, and safe PFCL medical devices are released in the market. It is necessary to promote to share properly the information related to adverse toxic effects of the PFCL among different regulatory authorities, publish in scientific journals, and circulate in national and international associations of ophthalmologists.

The European Union has created a framework to ensure the safety and efficacy of medical devices based on new regulation (EU-MDR; Regulation (EU) 2017/745 of the European Parliament and of the Council of 5 April 2017 on medical devices, amending Directive 2001/83/EC, Regulation (EC) No. 178/2002, and Regulation (EC) No. 1223/2009). It repeals Directive 93/42/EEC, which concerns medical devices, and Directive 90/385/EEC, which concerns active implantable medical devices. The regulation was published on 5 April 2017; it came into force on 25 May 2017. However, its application was postponed until 26 May 2021 because of the urgent priorities related to the coronavirus crisis. Now, posterior to 26 May 2021, it is mandatory to follow this new regulation for medical devices.

Besides European and ISO guidelines, the regional guidelines are available for biocompatibility assessments of medical devices. A notified body assesses a medical device following European and ISO guidelines; then, a country of the 
European Union can approve its application for CE-marking (a guarantee of safety). For example, in Spain, there is a national regulation that includes the following royal decrees:

- RD 1090/2015 regarding clinical trials

- RD 1591/2009 on regulation of sanitary products

- RD 437/2002 regarding licenses for manufacturers

Manufacturers have to comply with the European regulation 2017/745 to obtain the CE-marking, and if they want to enter the USA, they have to follow to what is stipulated by the Food and Drug Administration (FDA). The ISO releases international guidelines; however, they are not mandatory, but companies are required to consider them to manufacture and distribute their products.

Although regional and international guidelines are available, differences in proposed biocompatibility assessments or test methods lead to confusions and inefficiencies in generating the package of supporting nonclinical data. Several recent changes have been performed in these guidelines, and the impact of these changes has identified areas where a "standard approach" is not possible, allowing hurdles for global development of medical devices to persist. Nevertheless, a high level of consistency now occurs in ISO and FDA requirements [9]. Now, more extensive material characterization and increased determination of toxicological risks are required when evaluating new medical devices [13]. The purpose of this review is to compile the current situation related to PFCL, and to focus on the need of an appropriate, more robust, and precise biological test analysis, specifically direct test in which a test material interacts directly with live cells, along with chemical analysis. It is needed to be performed with each batch of the manufactured PFCL to improve the quality of PFCL and, in consequence, to avoid the clinical cases of visual impairment in future. Moreover, it is essential that the communication systems between the different health agencies of the different countries should be improved in order to communicate quickly the possible future problems, and there should be progress in common marketing authorization systems for any medical device such as in the European Union, the EU-MDR for European countries is enforced [14].

\section{Biological analysis}

The ISO 10993 has released a series of documents for providing numerous international guidelines for the protection of humans from potential biological risks arising from the use of medical devices [15]. These are generally accepted outright or as an alternative to most national regulatory directives or acts, although Japan and the USA require more stringency in some tests [16]. It is intended to describe the biological evaluation of medical devices within a risk management process, as part of the overall evaluation and development of each medical device. The two parts: Part 5, tests for in vitro cytotoxicity [17] and Part 12, sample preparation and reference materials [18] of the ISO 10993, provide several recommendations to be followed for performing in vitro biological analysis for certifying a medical device with CE-mark. One of the important requirements is these tests must be performed under GLP guidelines and by the trained staff. However, the industry GLP studies do not report the same risks of a chemical when it is published in a traditional academic peer-reviewed studies from academia $[19,20]$. There is a strong correlation between industry sponsorship and findings of safety [20]. Part 5 of the ISO 10993 guideline also recommends mainly two techniques for in vitro analysis: direct and indirect methods. The direct method consists in exposing the test sample directly to live cells; nevertheless, the indirect method is to expose the test sample indirectly to live cells. One of the reasons highlighted for the failure of the ISO standards is that it does not clearly define the test conditions, particularly the chemical characteristics of each test sample. The extract method and agar overlay method have been used to test the PFCL cytotoxicity. The reasons for the failure of these methods are described in detail in publications [2,3]. Two of the specific characteristics of PFCL are its high volatility and hydrophobicity that was avoided in biological tests for releasing CE-mark PFCL, and this is one of the reasons why so many cases of visual problems have been reported after intraocular surgery. Based on these characteristics, a new biological analysis technique has been developed (Patent: EP17805927.5A PCT/ES 2,017,070,365). This technique has already been recommended in the new version of ISO 16672:2020 "Ophthalmic implants-Ocular endotamponades." A similar method has been published lately [21]. It is based on the same PFCL characteristics identified for developing the previous direct biological test. This confirms the suitability of identified characteristics of PFCL for developing different direct cytotoxicity test methods.

Despite many reported clinical cases worldwide, there are papers justifying the appropriateness of the previous inuse methods for PFCL quality measurements. Recently, it is reported that toxicity is linked with $\mathrm{H}$-content concentration in PFCL and this concentration can be minimized using ultrapurification [22]. However, the research studies showed that there is no link between $\mathrm{H}$-content in PFCL with its toxicity [23]. In general, it is not possible to guarantee $100 \%$ purity of PFCL and toxicity depends on the type of impurities in the PFCLs. At this point, it must be noted that the toxicities (or vision loss) are not caused by PFCLs themselves but by the impurities present in the PFCLs. That is why the most believable and reasonable approach would be to combine the two methods, first a high purity determined by chemical analysis method and then a biological test method with each batch 
Table 2 False-negative results in case of mild toxic PFCL batches

\begin{tabular}{lll}
\hline PFCL & 30 -min exposure & \\
\cline { 2 - 3 } & 24-h cell growth & 72-h cell growth \\
\hline AlaOcta ${ }^{*}$ & $53 \%$ & $90 \%$ \\
Meroctane ${ }^{*}$ & $65 \%$ & $89 \%$
\end{tabular}

According to ISO 10993 guidelines, cell viability $>70 \%$ represents nontoxic and cell viability $<70 \%$ represents toxic

*Due to confidentiality, we cannot release batch numbers

for CE-marking. During the investigation, several critical points came to notice. One of the critical points is the selection of appropriate exposure periods of PFCL to live cells and posterior cell growth periods before performing toxicity measurement [2]. The probability of obtaining false-negative results (no cytotoxic) has been demonstrated experimentally in case of mild toxic PFCL batches as has been seen in case of the AlaOcta ${ }^{\circledR}[2]$ and further confirmed using Meroctane ${ }^{\circledR}$ (Table 2, due to confidentiality, we cannot release batch numbers). Therefore, it is recommended to have the specific attention on the mild toxic PFCL when performing cytotoxic tests [2]. To the best of our knowledge, Part 5 of the ISO 10993 guidelines mentions only the 24-h exposure period and cell growth period. Nevertheless, PFCL is used for a very short period ( $20 \mathrm{~min}$ to $1 \mathrm{~h}$ ) during vitreous surgery to treat complicated retinal detachments. To avoid the false-negative results, it is very recommendable to test the PFCL on different exposure periods such as $30 \mathrm{vs} 60 \mathrm{~min}$ and posterior cell growth periods such as 24 vs $72 \mathrm{~h}$, but this gap is not filled by the Part 5 of the ISO 10993 guidelines.

There are a number of techniques to demonstrate the purity of the PFCL but the presently reported clinical cases reinforce the need to improve the safety standards. Biological tests should be on top of all other measured quality standards. Because it is the only test that determines the real biological response of live cells against a manufactured PFCL and, thus, ensures that the PFCL is safe from the point of view of the biological response. The biological techniques improved by correcting the faults of the previously used techniques certainly promise the production of much safer PFCL. The new developed direct contact cytotoxicity test overcomes these faults because PFCL is directly in contact with live cells [2]. Nevertheless, biological tests must take into account the chemical characteristics of the product.

\section{Chemical analysis}

Pure PFCLs are considered biologically inert [24, 25]. Several companies in the market are involved in manufacturing the PFCL of different purity grades (mostly around 98-99.9\%), packaging and commercializing for human use
[26]. Chemical analytical techniques can detect several chemicals as impurities in very tiny amounts, normally present in parts per million level [22, 27, 28]. These analytical techniques would be the most cost-effective method of checking for the PFCL purity [29]. Nevertheless, presently reported clinical cases confirm that the current biological and chemical analytical techniques were unable to detect that the PFCL batches, which caused the visual problems, were toxic. Therefore, different chemical analytical techniques are essential to be used to determine the purity and impurity profile of PFCL, together with a direct cytotoxicity test to evaluate the biological response, and are the key parameters to ensure PFLC safety. Thus, QA data linked directly to biological response against each chemical element or impurity profiles can be obtained. The research studies have identified several impurities in previously reported toxic batches of PFCL (AlaOcta ${ }^{\circledR}$, BioOctane Plus ${ }^{\circledR}$, and Meroctane ${ }^{\circledR}$ ). Table 2 provides summarized information of detected and reported impurities of different batches of PFCL by our research group [1, 3, 28]. In case of AlaOcta $\AA$, a German group has also detected several impurities [22, 27]. The biggest problem with chemical methods is tracking down the possible contaminants. It is easy to detect them if they are known, but if they are not known, it is complicated.

Several toxic chemicals have been identified in these impurities and some of them are linked to the cause of the high level of toxicity. The very sensitive chemical analytical techniques detect most of the impurities present in a PFCL batch. Few of them have been reported in publications:

1: - Nuclear magnetic resonance (NMR) [23]

2: - Gas chromatography-mass spectrometry (GC-MS) [1, $3,26-28,30]$

3: - Infrared spectroscopy (FT-IR) [1, 28]

4: - Fluoride-selective potentiometry [22]

Three parts of the ISO 10993 "biological evaluation of medical devices" guidelines also release several recommendations regarding chemical analysis: Part 9: Framework for identification and quantification of potential degradation products [31], Part 18: Chemical characterization of materials [32], and Part 17: Establishment of allowable limits for leachable substances [33]. These guidelines provide regulatory standards for performing chemical analysis including the identification of a material, and the identification and quantification of the chemicals present in materials or finished medical devices. In Table 1 of the ISO 10993-18:2005(E) [32], ISO-recommended chemical analytical techniques are mentioned such as:

- dynamic mechanical thermal analysis (DMTA),

- differential scanning calorimetry (DSC),

- electron dispersal X-ray analysis, 
- scanning electron microscopy (EDX-SEM),

- Fourier-transform infrared spectroscopy (FT-IR),

- mass spectroscopy (MS) (mass spectroscopy is frequently combined with chromatographic techniques such as gas chromatography (GC), liquid chromatography (LC)),

- gel permeation chromatography (GPC),

- high-performance liquid chromatography (HPLC),

- inductively coupled plasma (ICP),

- nuclear magnetic resonance (NMR),

- UV-vis spectroscopy, X-ray photoelectron spectroscopy (XPS),

- X-ray fluorescence (XRF), and

- two-dimensional polyacrylamide gel electrophoresis (2D-PAGE).

Mostly, the chemical analytical techniques are performed for identified chemicals present as impurities. However, the chemicals, which are still unidentified, could be present as impurities. Chemicals could be present in very tiny amount that is out of range of the detection level of used analytical techniques. Nevertheless, many of these tiny amounts are sufficient to stimulate a very robust biological response [3].

All of these chemical analytical techniques support making standards to ensure the quality of the PFCL production. Thus, it can be avoided to include in the post manufacturing process to those PFCL batches that are not fulfilling the standards. However, they cannot be considered a solely alternative to an adequate biological analysis. For example, in our study, the FT-IR spectroscopy analysis showed that the nontoxic and toxic batches of the BioOctane Plus ${ }^{\circledR}$ product were similar; no differences were found in the spectra that could account for identify toxicity [3]. However, the GC-MS analytical technique detected the presence of the tributyltin bromide (TBT-Br) in the toxic batches of the BioOctane Plus ${ }^{\circledR}[3]$. However, it was established that the concentration was toxic because it was the experimental result in a cytotoxicity study, not only because of the GC analysis. This supports the researchers in establishing the reasons for the adverse clinical cases due to the BioOctane Plus ${ }^{\circledR}$ toxic batch. Another technique is to measure the $\mathrm{H}$-value of the PFCL by fluoride-selective potentiometry. This value has been described a quality parameter for PFCL in which, ideally, all of the hydrogen atoms have been replaced by fluorine atoms (PFCL) [22]. It has been included in the ISO 16672:2020 Ophthalmic implants-Ocular endotamponades [34] as an informative method to evaluate the partially fluorinated impurities of the PFCL that according to Menz et al. (2019) [22] can be unstable and lead to HF as a degradation product. Nevertheless, this methodology is already under question [2, 23].

The adverse clinical cases that have occurred in recent years indicate that a review of the analytical techniques to be used in each case is necessary. The choice of appropriate highly sensitive and specific chemical analytical techniques to determine the purity and identify the impurities in the PFCL is the basis for establishing product quality parameters. However, chemical analyses cannot predict an unexpected biological response, produced due to combinations of different impurities or the presence of toxic compounds below the detection limit of the equipment. In addition, PFCL impurities can vary from different brands and from batch to batch of the same brand. Also, some PFCL impurities could be leachable substances, which can be derived from packaging materials and could be toxic as xylols [25]. Therefore, the establishment of a detailed risk analysis and to perform a combination of chemical studies and biological cytotoxicity test in the packaged final product (i.e., a batch) previously to release into market is of vital importance.

\section{Direct cytotoxicity test for each batch}

The $100 \%$ purified PFCL is safe for patients. It is considered that PFCLs that are highly purified, which are tested for their physical and chemical characteristics, and biological response following the ISO guidelines and EU regulations are safe for patients. Nevertheless, in reality, the reported clinical cases show different scenarios. The manufacturers of toxic batches of the AlaOcta ${ }^{\circledR}$ or BioOctane Plus ${ }^{\circledR}$ assured that purity of their products was higher than $99 \%$ and they are safe $[1,3]$.

Several toxic compounds such as acids, alcohols, and esters have been detected in different PFO batches. It depends on their concentrations in the PFCL batch to produce low-tohigh adverse biological responses in live cells; however, all of them should be eliminated from the final products. Table 3 shows few impurities that have been detected in different batches of the PFCL of AlaOcta ${ }^{\circledR}$, BioOctane Plus ${ }^{\circledR}$, Meroctane ${ }^{\circledR}[1,3,22,28,30]$. Impurity profiles differ from one to another batch of the PFCL [1, 3, 22, 28, 30]. Batches' impurity profiles may change during their shelf life due to reactions among the reactive underfluorinated compounds. Pharmaceutical processing steps involving the impact of energy can trigger such changes [27]. There are several such reasons for the significant differences between batches derived from the same raw materials, such as in case of AlaOcta ${ }^{\circledR}$ toxicity [27]. Nevertheless, what is the biological response of each profile of impurities is difficult to predict without performing an appropriate cytotoxicity test. PFCL toxicity is batchdependent $[3,5,22,26,30]$. Considering all of these points, the biological response of each PFCL batch together with chemical analysis must be performed for releasing the final PFCL product to market. Another point is the storage time of the PFCL. In the case of AlaOcta ${ }^{\circledR}$, it has been demonstrated that the toxicity has been enhanced along storage time of the PFCL $[1,2]$. Therefore, it is very recommendable to measure the PFCL stability in several different conditions and adverse events that could generate. 
Table 3 Few reported impurities in different batches of PFCL

\begin{tabular}{lllll}
\hline PFCL & Batch number & $\begin{array}{l}\text { Biological } \\
\text { analysis }\end{array}$ & $\begin{array}{l}\text { Chemical analy- } \\
\text { sis technique }\end{array}$ & Chemical impurities \\
\hline AlaOcta ${ }^{\circledR}$ & 171,214 & Toxic & FT-IR/GC-MS & PFOA, DFH, EB, PX, DMB \\
& 061,014 & Toxic & FT-IR/GC-MS & PFOA, DFH, EB, PX, DMB \\
& 070,714 & Toxic & FT-IR-/GC-MS & PFOA, DFH, EB, PX, DMB \\
& 050,514 & Toxic & FT-IR/GC-MS & PFOA, DFH, EB, PX, DMB \\
BioOctane Plus ${ }^{\circledR}$ & $1,605,148$ & Toxic & GC-MS & TBT-Br \\
Meroctane ${ }^{\circledR}$ & OCT.01.2013 & Toxic & GC-MS & TDFD, DFH, HDFN, PFD, TDFH, \\
& & & & ESFU, PMCP, PDA, PDFO, HP, \\
& & & & PDFO \\
\hline
\end{tabular}

$G C-M S$, gas chromatography-mass spectrometry; FT-IR, Fourier-transform infrared spectroscopy; $T B T-B r$, tributyltin bromide, C12H27BrSn; $D F H, 1 \mathrm{H}, 1 \mathrm{H}, 7 \mathrm{H}$-dodecafluoro-1-heptanol; $E B$, ethylbenzene; $P F O A$, perfluorooctanoic acid; $P X$, P-xylene; $D M B$, 1,4-dimetyl-benzene; TDFD, 1,1,1,2,2,3,3,4,4,5,5,6,6-tridecafluorotridecane; $H D F N, 1 \mathrm{H}, 1 \mathrm{H}, 9 \mathrm{H}$-hexadecafluoro-1-nonanol; $P F D$, perfluorodecalin; TDFH, 1,1,1,2,2,3,3,4,4,5,6,6,6-tridecafluorohexane; $M D F H$, methyl 2,2,3,3,4,4,5,5,6,6,7,7-dodecafluoroheptanoate; $P H, 1 \mathrm{H}, 1 \mathrm{H}$-perfluoro-1-heptanol; $E S F U, 1 \mathrm{H}, 1 \mathrm{H}, 11 \mathrm{H}$-eicosafluoro-1-undecanol (ESFU), PMCP, perfluoro-N-(4-methylcyclohexyl) piperidine; $P D A$, perfluorododecanoic acid; $P D F O$, pentadecafluorooctanoic acid, methyl ester, $\mathrm{C}_{9} \mathrm{H}_{3} \mathrm{~F}_{15} \mathrm{O}_{2} ; H P, 1,1,1,3,3,3$-hexafluoropropane; $P D F O$, pentadecafluorooctanoic acid, isopropyl ester

*Cause of toxicity: there are several alcohols, acids, and other impurities. Therefore, it needs study to confirm that alcohol is the one that caused toxicity and not the rest. However, biological tests ensure that none of them are in the concentrations that produce toxicity

\section{Operationalization of safety monitoring of medical devices in India}

Medical devices are indispensable segment in a health care facility for the diagnosis, monitoring, treatment, or management of an array of disorders. Recently, public health safety concerns associated with medical devices like hip implant failure in India [35] drew attention to the need for a parallel system for the surveillance of medical devices. Government of India responded by commencing a program entitled Materiovigilance Programme of India (MvPI) in 2015 to ensure the safe use of medical devices in Indian population. The primary objective of this program is to identify the adverse events linked with the use of medical devices available in Indian market and to eliminate the possible risks through a well-placed reporting system. Post market surveillance for the medical devices is a mandatory requirement for the license holder in India. As per the Medical Devices Rules 2017 (MDR 2017), "the License Holder or its legal representative in India shall inform the State Licensing Authority (SLA) or Central Licensing Authority (CLA), as the case may be of the occurrence of any suspected unexpected serious adverse events, and take necessary action thereon, including any recall within 15 days of such event coming to the notice of the License Holder." Reporting device-related adverse events is voluntary for health care professionals or patients. As per MDR 2017, medical devices are classified into four classes in India ranging from class A to class D based on their risk imposing potential to the users/health care professionals/third party. PFCL is categorized under aqueous/vitreous humor replacement kit as a class D medical device indicating the hazardous potential of the PFCL. Therefore, extreme care is advised while handling PFCL.

MvPI is housed at the Indian Pharmacopoeia Commission (IPC), Ghaziabad, India, serving as a National Coordination Centre for the program. IPC receives device-related adverse events through its network of 150 medical device adverse event monitoring centres (MDMCs), 505 adverse drug reaction monitoring centres [(AMCs), established under the Pharmacovigilance Programme of India (PvPI) to monitor the safety of drugs and vaccines in India], marketing authorization holders (MAHs), and consumers.

For the seamless and easy reporting of adverse events linked with medical devices, IPC has developed an electronic adverse event reporting form (http://ipc.gov.in/ images/MEDICAL_DEVICE_ADVERSE_EVENT_ REPORTING_FORM_editable.pdf) and Field safety corrective action (FSCA) notification form (http://ipc.gov. in/images/FIELD_SAFETY_CORRECTIVE_ACTION_ NOTIFICATION_FSCA_FORM.pdf), a user-friendly mobile app and a toll-free helpline number (1800-1803024) for simultaneous reporting of adverse events. Reports are compiled and analyzed at IPC by applying the globally recognized scientific standards/parameters to ensure the quality of the adverse event reports. Then, reports are forwarded to relevant subject experts for their clinical review and causality assessment, and finally, reports enclosed with subject experts' opinions are discussed in core technical committee for the conclusion and recommendations, if any. Conclusions and recommendations are then forwarded to National Regulatory Authority (NRA) for necessary action. 


\section{Conclusion}

In the European Union, the manufacturers follow the ISO guidelines and the EU-MDR for QA to evaluate safety of medical devices such as PFCL by performing required tests and for acquiring $\mathrm{CE}$ certification for commercialization. This review tries to evaluate the current scenario about PFCL regulations and latest researches and is focused on addressing the need for adapting the current demand to avoid uncertainty on quality, safety, and market of the PFCL. In current scenario, biological tests based on direct exposure of PFCL to live cells are proved for its utility and necessary together with chemical analysis for dealing with PFCL-based cytotoxicity. However, recently approved in 2020, the ISO guideline "Ophthalmic implants-Ocular endotamponades. ISO/FDIS 16672.2 (https://www.iso.org/ standard/70806.html)." still does not provide a clear answer regarding the concerns.

\section{Declarations}

Ethics approval This article does not contain any studies with human participants performed by any of the authors.

Conflict of interest The authors declare no competing interests. Several authors from the University of Valladolid (GKS and JCP) are coauthors of a patent on a direct cytotoxicity analysis procedure that is the property of the University itself (Patent: EP17805927.5A PCT/ES 2017070365). The author CAI receives funding from AJL Ophthalmic S.A. Several authors are members of the ISO technical Committee involved in ISO 16672:2020 "Ophthalmic implants-Ocular endotamponades" new version (JCP, GKS, CAI).

\section{References}

1. Pastor JC, Coco RM, Fernandez-Bueno I et al (2017) Acute retinal damage after using a toxic perfluoro-octane for vitreo-retinal surgery. Retina 37:1140-1151. https://doi.org/10.1097/IAE.00000 00000001680

2. Srivastava GK, Alonso-Alonso ML, Fernandez-Bueno I et al (2018) Comparison between direct contact and extract exposure methods for PFO cytotoxicity evaluation. Sci Rep 8:1425. https:// doi.org/10.1038/s41598-018-19428-5

3. Coco RM, Srivastava GK, Andrés-Iglesias C et al (2019) Acute retinal toxicity associated with a mixture of perfluorooctane and perfluorohexyloctane: failure of another indirect cytotoxicity analysis. Br J Ophthalmol 103:49-54. https://doi.org/10.1136/bjoph thalmol-2017-311471

4. Januschowski K, Irigoyen C, Pastor JC et al (2018) Retinal toxicity of medical devices used during vitreoretinal surgery: a critical overview. Ophthalmologica 240:236-243. https://doi.org/10.1159/ 000488504

5. Tobalem SJ, Weinberger A, Kropp M et al (2020) Chorioretinal toxicity of perfluorooctane (Ala Octa): results from 48 surgical procedures in Geneva. Am J Ophthalmol 218:28-39. https://doi. org/10.1016/j.ajo.2020.05.014
6. Méndez-Martínez S, Calvo P, Rodriguez-Marco NA et al (2018) Blindness related to presumed retinal toxicity after using perfluorocarbon liquid during vitreoretinal surgery. Retina 38:1856-1864. https://doi.org/10.1097/IAE.00000 00000001783

7. Bentley D (1999) CE marking-what does it really mean? J Tissue Viability 9:11-15

8. Helmus MN, Gibbons DF, Cebon D (2008) Biocompatibility: meeting a key functional requirement of next-generation medical devices. Toxicol Pathol 36:70-80. https://doi.org/10.1177/01926 23307310949

9. Reeve L, Baldrick P (2017) Biocompatibility assessments for medical devices - evolving regulatory considerations. Expert Rev Med Devices 14:161-167. https://doi.org/10.1080/17434 440.2017.1280392

10. Donawa ME (1997) Complying with US and European complaint handling requirements. Med Device Technol 8:12-15

11. Lamph S (2012) Regulation of medical devices outside the European Union. J R Soc Med 105(Suppl 1):S12-21. https://doi.org/ 10.1258/jrsm.2012.120037

12. Carlos Pastor J (2021) Medical devices and the pendulum's law. Arch Soc Esp Oftalmol 96:453-454. https://doi.org/10.1016/j. oftal.2021.06.002

13. Bollen LS (2005) New trends in biological evaluation of medical devices. Med Device Technol 16:10-15

14. Pastor JC (2021) The need for the MDR (Medical Device Regulation). Allbiosolution 3:15-17

15. ISO 11.100.20 (2020) Biological evaluation of medical devices. https://www.iso.org/ics/11.100.20/x/. Accessed 16 Jan 2022

16. Schuh JCL (2008) Medical device regulations and testing for toxicologic pathologists. Toxicol Pathol 36:63-69. https://doi.org/10. $1177 / 0192623307309926$

17. ISO 10993-5 (2009) Biological evaluation of medical devices Part 5: tests for in vitro cytotoxicity. https://www.iso.org/cms/ render/live/en/sites/isoorg/contents/data/standard/03/64/36406. html. Accessed 18 Jan 2022

18. UNE-EN ISO 10993-12 (2013) Evaluación biológica de productos san... https://www.une.org/encuentra-tu-norma/busca-tunorma/norma/?c=N0050792. Accessed 16 Jan 2022

19. Becker RA, Janus ER, White RD et al (2009) Good laboratory practices and safety assessments. Environ Health Perspect 117:A482-A483. https://doi.org/10.1289/ehp.0900884

20. Tweedale T (2010) Good laboratory practices and safety assessments: another view. Environ Health Perspect 118:A194-A194. https://doi.org/10.1289/ehp.0901755

21. Romano MR, Ferrara M, Gatto C et al (2019) Evaluation of cytotoxicity of perfluorocarbons for intraocular use by cytotoxicity test in vitro in cell lines and human donor retina ex vivo. Transl Vis Sci Technol 8:24. https://doi.org/10.1167/tvst.8.5. 24

22. Menz D-H, Feltgen N, Menz H et al (2018) How to ward off retinal toxicity of perfluorooctane and other perfluorocarbon liquids? Invest Ophthalmol Vis Sci 59:4841-4846. https://doi.org/10.1167/ iovs. $18-24698$

23. Ruzza P, Gatto C, Ragazzi E et al (2019) H-Content is not predictive of perfluorocarbon ocular endotamponade cytotoxicity in vitro. ACS Omega 4:13481-13487. https://doi.org/10.1021/ acsomega.9b01793

24. Chang S, Ozmert E, Zimmerman NJ (1988) Intraoperative perfluorocarbon liquids in the management of proliferative vitreoretinopathy. Am J Ophthalmol 106:668-674. https://doi.org/10. 1016/0002-9394(88)90698-8

25. Georgalas I, Ladas I, Tservakis I et al (2011) Perfluorocarbon liquids in vitreoretinal surgery: a review of applications and toxicity. Cutan Ocul Toxicol 30:251-262. https://doi.org/10.3109/15569 527.2011 .560915 
26. Dresp JH (2020) Benchmarking different brands of perfluorocarbon liquids. Graefes Arch Clin Exp Ophthalmol. https://doi.org/ 10.1007/s00417-020-04964-6

27. Menz D-H, Feltgen N, Lechner T et al (2019) Hydrofluoric Acid and Other Impurities in Toxic Perfluorooctane Batches. Trans Vis Sci Tech 8:24-24. https://doi.org/10.1167/tvst.8.3.24

28. Srivastava GK, Andrés-Iglesias C, Coco RM et al (2020) Chemical compounds causing severe acute toxicity in heavy liquids used for intraocular surgery. Regul Toxicol Pharmacol 110:104527. https://doi.org/10.1016/j.yrtph.2019.104527

29. Chang S, Simpson RN (2017) Impure perfluorocarbon liquids: a preventable tragedy. Retina 37:1019-1020. https://doi.org/10. 1097/IAE.0000000000001663

30. Coco-Martin RM, Andrés-Iglesias C, Srivastava GK et al (2021) Intraocular toxicity caused by MEROCTANE perfluorocarbon liquid. Sci Rep 11:599. https://doi.org/10.1038/s41598-020-79561-y

31. ISO 10993-9 (2009) Biological evaluation of medical devices Part 9: framework for identification and quantification of potential degradation products. https://www.iso.org/cms/render/live/en/ sites/isoorg/contents/data/standard/04/40/44049.html. Accessed 16 Jan 2022
32. ISO 10993-18 (2020) Biological evaluation of medical devices - Part 18: chemical characterization of medical device materials within a risk management process. https://www.iso.org/cms/ render/live/en/sites/isoorg/contents/data/standard/06/47/64750. html. Accessed 16 Jan 2022

33. ISO 10993-17 (2002) Biological evaluation of medical devices - Part 17: establishment of allowable limits for leachable substances. https://www.iso.org/cms/render/live/en/sites/isoorg/conte nts/data/standard/02/39/23955.html. Accessed 16 Jan 2022

34. ISO 16672 (2020) Ophthalmic implants - Ocular endotamponades. https://www.iso.org/cms/render/live/en/sites/isoorg/conte nts/data/standard/07/08/70806.html. Accessed 16 Jan 2022

35. Correspondent BI (2018) India patients reject government's compensation scheme for recalled hip implants. BMJ 363:k5254. https://doi.org/10.1136/bmj.k5254

Publisher's note Springer Nature remains neutral with regard to jurisdictional claims in published maps and institutional affiliations. 